$13^{\text {th }}$ International Conference on

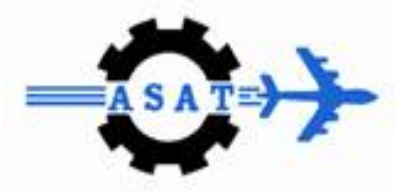

\title{
Protection of Honeycomb Sandwich Armours Against the Ballistic Attacks
}

\author{
H. M El-Fayad", M. M Abdel-Wahab ${ }^{*}$, H. M.Farag ${ }^{*}$ and A. A El-Ashaal ${ }^{* *}$
}

\begin{abstract}
Evolution of the ballistic threat has taken place, principally, in the contexts of general war, terrorism and crime. The threat has been developed to cause injury or damage to personal, land vehicles, ships, aircraft and structures. Inert projectiles will cause only localized damage to structural targets and therefore normally constitute a less potent threat to the survival of the structure than rounds which have high explosive contents. This paper describes the spectrum of ballistic threats on armoured structures. The results from FEM simulations of steel projectile penetrating sandwich honeycomb armours are discussed. The simulations are performed in 3D AUTODYN software [1]. Finally, the armours with composite systems and different materials subjected to blast loads will be discussed. The results show that the ceramic-faced armours cause reduction in projectile exit velocity by about $29.4 \%$ and $39.6 \%$ for ceramic thicknesses $10 \mathrm{~mm}$ and $20 \mathrm{~mm}$ respectively. Also the result indicate that the honeycomb reduce the displacement due to blast loads by about $77.24 \%$, only with $3.586 \%$ increasing in the total weight of the armours.
\end{abstract}

Keywords: Honeycomb, Armours, Blast load, Penetration.

\begin{abstract}
Abbreviations
HESH : High explosive squash head

F.E.M : Finite element method

RHT : Strength model for the concrete
\end{abstract}

\section{Objective}

The primary objectives of this paper are to study the resistance of honeycomb sandwich armours filled with different materials withstand both the blast and penetration accidents.

\section{Introduction}

The aims of the armours are to prevent the penetration and contribute with increasing the resistance of the structures against the blast effects. This paper studies the reduction of the exit projectile velocity. The work was done using steel projectiles with total length $552 \mathrm{~mm}$ devided into a cylindrical part and ogive nose part. In this study the concrete, steel, ceramic (SiC), sand and rubber are used as filler materials for the honeycomb sandwich armours. In addition the models were tested under the blast overpressure 11.6 bar.

\footnotetext{
* Egyptian Armed Forces, Egypt

** Professor. Director of Construction Research Institute, National Water Research Center, Egypt
} 


\section{Background}

\subsection{Ballistic Threat}

A ballistic threat [2] is normally categorized as either a kinetic energy or a chemical energy threat. A kinetic energy threat is one in which penetration is achieved by an inert projectile, by virtue of the fact that it possesses kinetic energy. The kinetic energy will have been given to the projectile either at launch, as in a gun, or during flight, as in the case of a rocketpowered missile system. Examples of kinetic energy threats include most small to medium caliber rounds, and the long rod penetrator.

A chemical energy threat is one in which the energy is delivered to the target as stored chemical energy in the form of high explosive. Examples of the chemical energy threat include shaped-charge rounds, and high explosive squash head (HESH) rounds. In the shapedcharge round as show in Fig. 1, the explosive is detonated by fusing system just prior to impact, forming the conical metal liner into a highly penetrative jet. In the HESH round a part of explosive is detonated on the face of the target shortly after impact, causing damage in the target by a combination of blast waves and stress waves.

\subsection{Armor Materials}

Conventional armor materials are typically made of steel, aluminum, or other hard metals. Although these metallic materials primarily perform a structural function, they provide reasonably good ballistic protection at appropriate thicknesses (or areal densities). New and innovative approaches involving lighter materials such as ceramics and polymers have become absolutely essential. Several recent studies [3-4] have utilized monolithic ceramics such as Alumina (Al2O3), Boron Carbide (B4C), Silicon Carbide (SiC), and Titanium Diboride (TiB2) for developing personnel and vehicular ballistic protection armor systems. Owing to their low specific gravity, and high stiffness, hardness, strength and thermal stability, the ceramic-based systems have shown potential for improving upon current standards for ballistic performance, which includes multi-hit capability. Also the concrete material widely used in protection against the rockets or missiles. In this study the concrete, steel, ceramic (SiC), gravel, sand and rubber have been used as protection materials of the armours with participating with honeycomb.

\subsection{Penetration, Perforation and Ballistic Limit Velocities}

The penetration of projectiles into targets involves complex mechanical interactions. By convention [5] the following simplifying definition are adopted. When a round has entered a target but not passed completely through it, it is said to have 'penetrated' the target. The depth of penetration is given by the distance 'p' as show in Fig. 2a. When a round passes completely through a target, it is said to have 'perforated' the target, as showing in fig.2b. In theory, the ballistic limit velocity is the velocity at which the projectile will just perforate the target and emerge from the target with zero residual kinetic energy.

In practice, of a number of identical projectiles fired at identical speed at a single target, some will perforate and some will not. The ballistic limit velocity is therefore defined as the velocity at which a projectile has a $50 \%$ probability of perforating the target and is given the symbol V50. 


\section{FEM Analysis}

FEM provide a detailed understanding of the interaction between projectiles and target. Computer-based methods can provide the researcher or designer with a great deal of valuable information about the penetration process. Such methods are particularly useful when dealing with rounds or target having complex geometries or utilizing multiple materials as in this paper.

A FE model with good material models should be able to predict the crater size and the depth of penetration of a steel projectile impacting a target.

In this paper for ensure and verification that the model can predict the depth of penetration and crater size, the results obtained from rerun FEM simulation of a steel projectile penetrating a concrete target have been compared to experimental results made by (Hakan. et. all) [6].

Analyses with AUTODYN [1] by using the RHT model for the concrete target and Johnson \& Cook strength model for the steel projectile have been used, and the data listed in table (1) and (2) respectively.

\subsection{Validation Constitutive Model:}

In 1999 a series of benchmark tests with instrumented steel projectiles impacting on concrete target were conducted at the Bofors test centre in Karlskoga [6]. The tests were a cooperation project with DERA (Defense Evaluation and Research Agency) in the UK, FFI (Forsvarets Forskningsinstitutt) in Norway, TNO (The Netherlands Organization for Applied Scientific Research) from Holland and FOA Sweden as participants and an important aim was to obtain reliable data for numerical simulations. As a short review, the test was done with steel projectiles with total length $552 \mathrm{~mm}$ devided into a cylindrical part and ogive nose part. The cylindrical part has a length of $324 \mathrm{~mm}$ and a radius of $76 \mathrm{~mm}$, while the ogive nose radius is $380 \mathrm{~mm}$, nose length $228 \mathrm{~mm}$, total mass $46.2 \mathrm{~kg}$ impacting velocity $460 \mathrm{~m} / \mathrm{s}$ with concrete targets with diameter $240 \mathrm{~cm}$ and thickness $75 \mathrm{~cm}$ as shown in Fig. 3.

The initial 3D penetration simulations were done using a Lagrange formulation of the target as well as the projectile.

The element mesh size is about $21.5 \mathrm{~mm}$ and $7.4 \mathrm{~mm}$ along and across the projectile axis respectively.

The target is $75 \mathrm{~cm}$ thick with a radius of $120 \mathrm{~cm}$ divided into 2 circumferential cylindrical subgrids with outer cylinder enclosing the inner. The inner, central, cylinder has a radius of 50 $\mathrm{cm}$ and the outer cylinder covers the remaining part up to the total radius of $120 \mathrm{~cm}$. the inner cylinder has a constant element size of $10 \mathrm{~mm}$, while the element size of the enclosing cylinder gradually increases from $10 \mathrm{~mm}$ to $41.1 \mathrm{~mm}$. this limits the number of elements far away from the impact and thus reduces the computational time. In this study, the model identity with number (B99330) [6] (1/4-symmetry) was chosen to examine the exit velocity. The damage of concrete obtained by [6] and that obtained in this study shown in Fig. 4.

Fig. 4 shows the correlation of damage distribution for $1 / 2$-symmetry model occurred in the concrete target obtained by Hansson [6] and present study. 
The mean velocity time history with the experimental data is drawing in Fig. 5. The mean values of velocity with time history for the benchmark test were obtained using radar measurements. For comparison, the experimental exit velocity was approximately $190 \mathrm{~m} / \mathrm{s}$, while average exit velocity for the projectile in present study was $206 \mathrm{~m} / \mathrm{s}$ the difference is $7.77 \%$ and the energy error is $7.49 \%$ these comparisons show that the RHT model for concrete and the Johnson \& Cook strength model for the projectile material give reasonable simulation, for this reason same properties of concrete and the projectile mentioned above were taken in following sections. Fig. 6 shows the meshing for the verification model.

\subsection{Models Description:}

In this study ten models were tested to evaluate the effect of pith material to resist the penetration of the projectile mentioned above. Each model has been meshed into same type of elements and same numbers of nodes for the resemblance geometries. The dimension for general model $(1400 \mathrm{~mm} \times 2600 \mathrm{~mm} \times 220 \mathrm{~mm})$, as shown in Fig. 7 , the boundary condition is simply support at four sides of the back plate of the model. For abbreviating only the region of the penetration were viewed in detail (A). The detail (A) of construction for each model is shown in figures (8) to (19), the models are divided into two groups as follows:

Group1: contains the models: model1, model2, model3 and model4, where the configuration for the front plate, back plate, tire, and the hexagonal honeycomb core are the same in these models.

Group2: contains the models: model5, model6, model7, model8 and model9. which coincide with group1 with the configuration of the back plate, tire, and the hexagonal honeycomb core but the thickness of the front plate is equal to $20 \mathrm{~mm}$ in this group.

The précis descriptions of the models are as follows:

Model 1: the model consists of two steel plates with thickness equals to $10 \mathrm{~mm}$ for each one, also a tire of steel with height $200 \mathrm{~mm}$ and thickness $10 \mathrm{~mm}$, in addition to a hexagonal honeycomb core with thickness equals to $1 \mathrm{~mm}$ trapped between the plates, the details are as shown in Fig. 8.

Model 2: it is the same as model 1 except that it has concrete pith with same material properties as mentioned in section (4), the details are shown in Fig. 9.

Model 3: it is the same as model 1 except that it is filled with rubber pith type Arruda-Boyce with same material properties as illustrated in table (3). Arruda-Boyce type is generally applicable ranges of strain Up to 300 \%. The details are illustrated in Fig. 10.

Model 4: it is the same as model 1 except that it is filled with sand, the sand properties as drawn in figures (20 to 23). The sand with Compaction equation of state, MO Granular strength model, Hydro tensile limit $=-1 \mathrm{kpa}$. The details as illustrated in Fig. 11 .

Model 5: it is the same as model 2, but the front plate has the thickness of $20 \mathrm{~mm}$, the details as shown in Fig. 12.

Model 6: it is the same as model 5 except that additional layers of ceramic Silicon Carbide (SIC) with thicknesses $10 \mathrm{~mm}$ and $20 \mathrm{~mm}$ clad the front steel plate. In general, the ceramic 
layer bondings with steel plate using an epoxy resin cement. The properties for ceramic are illustrated in table (4) and the details as illustrated in Fig. 13.

Model 7: it consists of two resemble armours filled with concrete, with same material properties as mentioned in section (4), the distance between two armours is one meter and the details are illustrated in figures (14) and (15).

Model 8: it is the same as model 5 with oblique impact angle of 15 . The details as illustrated in Fig. 16.

Model 9: it is the same as model 5 with oblique impact angle of 30 degree. The details as illustrated in Fig. 17.

Model 10: it is filled with two different a concrete layer with thickness $100 \mathrm{~mm}$ in front and a rubber layer with the same thickness in the back. Both layers have the same material properties as mentioned in the previous section. The details are illustrated in Fig. 18.

\subsection{Result Analysis :}

Fig. 23a shows the projectile exit velocity versus time for the models in group 1 . It can be noted that the model 1 (no pith) causes only a reduction by $4 \%$ in the projectile exit velocity which concluded that the honeycomb with no filling material is not appropriate to protect against penetration due to the weak effect to resist the high projectile's kinetic energy.

While the model 3 (Rubber pith) causes a reduction of about $8 \%$ of the projectile exit velocity, the model 4(Sand pith) reducing the projectile exit velocity by about $17 \%$. These results leads to that; using sand as a pith material reducing the projectile exit velocity 4.25 times that of no pith and 2.125 times that of rubber pith but the weight increase by $67.6 \%$.

Also it can be noted that the minimum projectile exit velocity occurs in concrete pith, and the reduction is about 1.294 times that of sand pith, with increasing weight of about $42.4 \%$. These results leads to that; using concrete as a pith material gives the highest resistance against the specified projectile among other materials. Fig. 23b shows the reduction rate in the projectile exit velocity for the models the same last group.

Fig. 24 shows the time histories of the projectile exit velocities for the model 2 (concrete pith with front steel plate $t=10 \mathrm{~mm}$ ), model 5 (concrete with addition thickness of front steel plate $\mathrm{t}=20 \mathrm{~mm}$ ) and the model 6 (steel front plate $\mathrm{t}=20 \mathrm{~mm}$ with addition layers of ceramic $\mathrm{t}=10$ $\mathrm{mm}$ and $\mathrm{t}=20 \mathrm{~mm}$ ). It can be noted that the model 6 causes a reduction in projectile exit velocity with about $29.4 \%$ and $39.6 \%$ for ceramic thicknesses $10 \mathrm{~mm}$ and $20 \mathrm{~mm}$ respectively, which equal to the reduction in case of concrete pith only 1.34 and 1.8 times while the weight of the armours increases by $4.2 \%$ in case ceramic thickness $t=10 \mathrm{~mm}$, also the reduction in velocity by 1.13 times that of model 5 . That leads to using a ceramic layer of $10 \mathrm{~mm}$ thickness causes an optimum reduction in the projectile exit velocity with minimum increasing in the armours weight. So when the projectile strikes the ceramic layer, the tip shatters, and the ceramic progressively breaks into a cone of fractured material, which subsequently spreads the impact load over a wide area of backing, energy being transferred from the projectile to the target. As the projectile penetrates the broken ceramic, the ductile back plate deforms and absorbs the kinetic energy of impact. 
Also addition layer of ceramic with thickness $20 \mathrm{~mm}$ was tested in (model 6) and compared with previous models.

Figure 13 (right) shows the damage occurred to the nose of the projectile and fragmentation of the ceramic layer.

Figure 25 shows the reduction rate in projectile exit velocity for the models mentioned in Fig. 24. Fig. 26 shows the projectile exit velocity time history for the Model 7(double armours), as shown in figures (14) and (15), it can be noted that the first armour causes reduction of the projectile velocity by $26 \%$. The projectile impacts the second armour with velocity $327.731 \mathrm{~m} / \mathrm{sec}$ and exit with velocity $176.278 \mathrm{~m} / \mathrm{sec}$ at time $6 \mathrm{~ms}$, it loses about $61.7 \%$ of its initial velocity. The projectile spends longer time to pass through the second armour, which is $3 \mathrm{~ms}$, while it takes $2 \mathrm{~ms}$ to passing through the first armours, which indicated that this system of the successive armours is the highest protection against the specified projectile, another advantage of this system is that a comparatively light weight that leads to easy movement for each armour.

Figure 27 shows the damage occurred in the concrete material in the first and second armours, it can be noted that the damage in the second armour is greater than that of the first armour.

Figure 28 shows the loosing of the projectile kinetic energy versus time, when it is passing through the two armours, the figure shows that the projectile loses about $85.3 \%$ of its kinetic energy. The target experienced localized deformation in the vicinity of the point of impact as well as overall structural deformation as shown in Fig. 27.

Figure 29 shows the projectile exit velocity time history for the model 5 (normal impact), Model 8 (oblique impact by 15 degree), and Model 9 (oblique impact by 30), it can be noted that the reduction in exit velocity when the projectile impact the armours with 15 and 30 degree oblique angles are $27 \%$ and $29 \%$ respectively. They are greater than that case of the normal impact which is $26 \%$. This result indicates that the oblique of the outer layers of the target is very important for reducing the projectile velocity. Trials results indicate that the optimum plate thickness ratio may be dependent upon obliquity, but the variations in the results, indicates that there is a need for further work in this area.

Figure 30 shows the projectile exit velocity time histories for the model 2 (concrete pith), and Model 10 (concrete $=100 \mathrm{~mm}$ and rubber $=100 \mathrm{~mm}$ ), it can be noted that the pith with concrete material (model 2) causes higher loosing of the projectile velocity than that caused by using two material (Model 10) (concrete $=100 \mathrm{~mm}$, and rubber=100 mm), the reduction is about $22 \%$ and $13.3 \%$ respectively due to the weakness of the rubber to resist against the specified projectile.

\section{5. Effect of Materials Used as a Pith (Filler) in the Behavior of Sandwich Armours Against Blast Loads:}

The performance of multi available natural materials that can be used as pith for sandwich steel armours, together with the steel core; these materials are feasible to enhance the out-ofplane resistance to give reasonable response of the armours against blast loads. The first four models mentioned in section (3.6) (group 1) will be tested against the blast loads to investigate the effect of these filler materials on the behavior of honeycomb armours. 
Figure 32 shows the different displacements time histories for the target point 22 which located at the center of the front plate for the models: model 1( no pith), model 2 (concrete pith), model 3 (rubber pith), model 4 (sand pith) subjected to blast load Fig. 31. It can be noted that the maximum displacements for these models, $(1,2,3$, and 4$)$ occurs in the positive phase of the load and they are $46.22 \mathrm{~mm}, 4.139 \mathrm{~mm}, 32.21 \mathrm{~mm}, 39.127 \mathrm{~mm}$ respectively. The maximum displacement resulted in the model 1, while the minimum displacement occurs in the model 2 due to high stiffness of the concrete material in all directions. This implies that the concrete material may be used as a pith material when the minimum displacement is recommended. The disadvantage of the heavy weight which causes a movement problem can be overcame by using a lighter material such as sand or rubber. The rubber material is a lightest material among the others; it has sufficient ductility to give elastic deformations of the armours . The maximum displacement of about $32.21 \mathrm{~mm}$ occurs when using the rubber as a pith material; this value is smaller than that occurs in the model 4 (sand pith) by about $18 \%$.

Figure 33 shows the internal energy absorbed of the models in group 1, the maximum internal energy at time 1.31E-002 sec is $(70314.7 \mathrm{~J}, 61311.3 \mathrm{~J}$, $54583.7 \mathrm{~J}$, and $31255.8 \mathrm{~J}$ ) for the models 1, 4, 3 and 2 respectively. This result leads to that the model 2 (concrete pith) has been absorbed a minimum energy among the others, so the displacement propagated in the model 2 (concrete pith) was the minimum.

Figure 34 shows that the stress propagation in the front and back plate of the armours in model 3 (rubber pith) at time 1.554E-002 sec (in the suction phase), the figure shows that the stresses are less than the yield stress of steel, or in other words the plates remained usable. It seems the rubber pith, forms a relaxant bed for the plates, so, the rubber can be used as a pith material for the interior armours, where the protection against penetration is not required.

Figure 35 shows the stress propagation in the hexagonal steel core in model 3 (rubber pith) at time 1.554E-002 sec (in the suction phase), the figure shows that the stresses are less than the yield stress of steel, so the rubber pith gives a sufficient protection to the components of the armours subjected to blast load.

Figure 36 shows the damage pattern of the concrete material in model 2 (concrete pith) at time 2.079E-002 sec (in the suction phase), the figure shows that a $20 \%$ of concrete area suffer a maximum damage, while the remaining surface suffer a different levels of damage.

Figure 37 shows the displacement time history for the model 1 (no pith), model 4 (sand pith) and model 11 (sand pith without honeycomb), the effect of honeycomb on the response of the armour is obvious, the maximum displacement is about $171.93 \mathrm{~mm}$ in the model 11 at time $1.116 \mathrm{E}-002 \mathrm{~ms}$, where while it is $39.127 \mathrm{~mm}$ in model 4 at time $6.2502 \mathrm{E}-002 \mathrm{~ms}$, which indicates that the honeycomb reduce the displacement by $77.24 \%$ only with $3.586 \%$ increase in the total weight of the armours.

\section{Conclusion}

From the previous study, the following conclusion can be drawn out:

- The AUTODYN code satisfactory simulates the benchmark test.

- The honeycomb armours with no filling material is not appropriate for penetration protection. 
- The rubber pith reducing projectile exit velocity by $8 \%$., while sand pith is reducing it by $17 \%$. So, using sand as a pith material for the specified armours reducing the projectile exit velocity up to 4.25 times that without pith and up 2.125 times that of the rubber pith, with increasing weight by about $67.6 \%$.

- The minimum projectile exit velocity occurs using concrete pith, the reduction in exit velocity is up to 1.294 times that of sand pith with increasing weight by $42.4 \%$ which means that, using the concrete as a pith material give highest resistance against the specified projectile among the other material studied.

- Ceramic layers reducing the projectile exit velocity by $29.4 \%$ and $39.6 \%$ for layer's thicknesses $10 \mathrm{~mm}$ and $20 \mathrm{~mm}$ respectively.

- Using a ceramic layer causes damage to the nose of the projectile.

- A system with double armours is appropriate for protection against penetration.Using double armours to protect against the projectile. Causes reducing of the projectile velocity with rate equal to about $61.7 \%$ respect to initial velocity, and the projectile spent long time to pass through the second armours ,

- The oblique of the outer layers of the target is very important for reducing of projectile velocity.

- The study reveals that the honeycomb reduces the displacement by $77.24 \%$ only with $3.586 \%$ increas in the total weight of the armours.

\section{References}

[1] Manual for AUTODYN software Agency of Century Dynamics Company (2003).

[2] J.G. Hetherington, P. D. Smith, Blast and Ballistic Loading of Structure. Cranfield University 1994.

[3] Medvedovski, E., Am. Ceram. Soc. Bull “Alumina Ceramics for Ballistic Protection,”, 81[3] pp.27-32 (2002).

[4] Ray, D. et al. "Hardness/Toughness Relationship for SiC Armor,”, Ceramic Engineering and Science Proceedings, 24[3] pp.401-410 (2003).

[5] J.G. Hetherington, The Terminal Ballistic performance of Small to Medium Caliber Kinetic Energy Ammunition, School of Mechanical, Materials and Civil Engineering, Royal Military College of Science (Cranfield) Report No 0303-003, 1984.

[6] Hakan Hansson, Peter Skoglund, Simulation of Concrete Penetration in 2D and 3D with the RHT Material Model, Swedish Defense Research Agency (2002). 
Table 1 Input Data for Concrete Target with P-Alpha Equation of State and RHT Strength Model

\begin{tabular}{|l|l|l|l|}
\hline Porous density $\left(\mathrm{g} / \mathrm{cm}^{3}\right)$ & 2.39 & Shear Modulus (MPa) & 18000 \\
\hline Porous sound speed $(\mathrm{m} / \mathrm{s})$ & 3000 & Compressive Strength f'c (MPa) & 92 \\
\hline $\begin{array}{l}\text { Initial compaction pressure } \\
(\mathrm{MPa})\end{array}$ & 80 & Tensile Strength ft & $0.057 \mathrm{fc}$ \\
\hline $\begin{array}{l}\text { Solid compaction pressure } \\
(\mathrm{MPa})\end{array}$ & 1800 & Shear Strength fs & $0.3 \mathrm{fc}$ \\
\hline Compaction exponent $\mathrm{n}$ & 5 & Failure Surface Parameter A & 1.9 \\
\hline EOS Solid & Polynomial & Failure Surface Parameter N & 0.6 \\
\hline Compaction curve & Standard & Tens./Compr. Meridian Ration & 0.6805 \\
\hline Reference density $\left(\mathrm{g} / \mathrm{cm}^{3}\right)$ & 2.54 & Brittle to Ductile Transit. & 0.0105 \\
\hline Parameter $\mathrm{A}_{1}(\mathrm{MPa})$ & 40000 & G(elas.)/G(elas-plas.) & 2 \\
\hline Parameter $\mathrm{B}_{0}$ & 1.22 & Elastic Strength & $0.8 \mathrm{ft}$ \\
\hline Parameter $\mathrm{B}_{1}$ & 1.22 & Elastic Strength & $0.75 \mathrm{f}^{\prime} \mathrm{c}$ \\
\hline Parameter $\mathrm{T}_{1}(\mathrm{MPa})$ & 40000 & Residual Strength Const.B & 1.6 \\
\hline Reference Temperature $(\mathrm{k})$ & 300 & Residual Strength Exponent M & 0.61 \\
\hline Specific heat $(\mathrm{j} / \mathrm{kgk})$ & 640 & Comp. Strain Rate Exponent $\alpha$ & 0.01 \\
\hline Strength model & $\begin{array}{l}\text { RHT } \\
\text { CONCRETE }\end{array}$ & Tens. Strain Rate Exponent. $\delta$ & 0.013 \\
\hline Failure model & $\begin{array}{l}\text { RHT } \\
\text { CONCRETE }\end{array}$ & Tensile Failure model & $\begin{array}{l}\text { Hydro } \\
\text { Tens. }\end{array}$ \\
\hline Damage constant $\mathrm{D}_{1}$ & 0.08 & Min. Strain to Failure & 0.05 \\
\hline Damage constant $\mathrm{D}_{2}$ & 1 & Residual Shear Modulus Frac. & 0.13 \\
\hline
\end{tabular}

Table 2 Input Data for Steel Projectile with Shock Equation of State and JohnsonCook Strength Model

\begin{tabular}{|l|l|l|l|}
\hline Equation of state & Shock & Strength Model & $\begin{array}{l}\text { Johnson- } \\
\text { Cook }\end{array}$ \\
\hline Reference density $\left(\mathrm{g} / \mathrm{cm}^{3}\right)$ & 7.75 & Shear Modulus $(\mathrm{MPa})$ & 81800 \\
\hline Gruneisen coefficient & 2.17 & Yield Stress $(\mathrm{MPa})$ & 1539 \\
\hline Parameter $\mathrm{C}_{1}(\mathrm{~m} / \mathrm{s})$ & 4569 & Hardening Constant $(\mathrm{MPa})$ & 477 \\
\hline Parameter $\mathrm{C}_{2}(\mathrm{~m} / \mathrm{s})$ & 1.49 & Hardening Exponent & 0.18 \\
\hline Bulk Modulus $(\mathrm{MPa})$ & 159000 & Strain Rate Constant & 0.012 \\
\hline Reference Temperature $(\mathrm{K})$ & 300 & Thermal Softening Exponent & 1 \\
\hline Specific Heat $(\mathrm{J} / \mathrm{kgK})$ & 477 & Melting Temperature $(\mathrm{K})$ & 1763 \\
\hline
\end{tabular}


Table 3 Input Data for Rubber Type Arruda-Boyce with Hyperelastic Equation of State and Strength Model

\begin{tabular}{|l|l|l|l|}
\hline Equation of State & Hyperelastic & Model & Arruda-Boyce \\
\hline Reference density $\left(\mathrm{g} / \mathrm{cm}^{3}\right)$ & $1.00000 \mathrm{E}+00$ & Shear Modulus $(\mathrm{kPa})$ & $2.70000 \mathrm{E}+02$ \\
\hline Reference Temperature $(\mathrm{K})$ & $2.93000 \mathrm{E}+02$ & Lambda & $5.14782 \mathrm{E}+00$ \\
\hline Strength & Hyperelastic & Comp. Coeff. D $(/ \mathrm{kPa})$ & $5.00000 \mathrm{E}-07$ \\
\hline
\end{tabular}

Table 4. Input Data for Ceramic Type Silicon Carbide (SiC) with Polynomial Equation of State and Johnson-Holmquist Strength Model

\begin{tabular}{|c|c|c|c|}
\hline Equation of State & Polynomial & Strain Rate Constant, C & 9.00000E-03 \\
\hline Reference density $\left(\mathrm{g} / \mathrm{cm}^{3}\right)$ & $3.21500 \mathrm{E}+00$ & $\begin{array}{l}\text { Max. Fracture Strength, } \\
\text { SFMAX }(\mathrm{kPa})\end{array}$ & $1.30000 \mathrm{E}+06$ \\
\hline Bulk Modulus $\mathrm{A}_{1}(\mathrm{kPa})$ & $2.20000 \mathrm{E}+08$ & $\begin{array}{l}\text { Failed Strength Constant, } \\
\text { ALPHA }\end{array}$ & 4.00000E-01 \\
\hline Parameter $\mathrm{A}_{2}(\mathrm{kPa})$ & $3.61000 \mathrm{E}+08$ & Failure & $\begin{array}{l}\text { Johnson } \\
\text { Holmquist }\end{array}$ \\
\hline Parameter $\mathrm{T}_{1}(\mathrm{kPa})$ & $2.20000 \mathrm{E}+08$ & Hydro Tensile Limit(kPa) & $-7.50000 \mathrm{E}+05$ \\
\hline Reference Temperature(K ) & $2.93000 \mathrm{E}+02$ & Model Type (JH1) & Segmented \\
\hline Strength & $\begin{array}{l}\text { Johnson- } \\
\text { Holmquist }\end{array}$ & $\begin{array}{l}\text { Damage } \quad \text { Constant, } \\
\text { EFMAX }\end{array}$ & $1.20000 \mathrm{E}+00$ \\
\hline Shear Modulus(kPa ) & $1.93500 \mathrm{E}+08$ & $\begin{array}{l}\begin{array}{l}\text { Damage } \\
(\mathrm{kPa})\end{array} \\
\text { Constant, } \quad \mathrm{P}_{3}\end{array}$ & $9.97500 \mathrm{E}+07$ \\
\hline Model Type (JH1) & Segmented & Bulking Constant, Beta & $1.00000 \mathrm{E}+00$ \\
\hline $\begin{array}{lll}\text { Hugoniot Elastic } & \text { Limit, } \\
\text { HEL }(\mathrm{kPa}) & & \\
\end{array}$ & $1.17000 \mathrm{E}+07$ & Damage Type & $\begin{array}{l}\text { Instantaneous } \\
\text { (JH1) }\end{array}$ \\
\hline $\begin{array}{l}\text { Intact Strength Constant, } \\
S_{1}(\mathrm{kPa})\end{array}$ & $7.10000 \mathrm{E}+06$ & Tensile Failure & Hydro (Pmin) \\
\hline $\begin{array}{l}\text { Intact Strength Constant, } \\
\mathrm{P}_{1}(\mathrm{kPa})\end{array}$ & $2.50000 \mathrm{E}+06$ & Erosion & $\begin{array}{l}\text { Geometric } \\
\text { Strain }\end{array}$ \\
\hline $\begin{array}{l}\text { Intact Strength Constant, } \\
\mathrm{S}_{2}(\mathrm{kPa})\end{array}$ & $1.22000 \mathrm{E}+07$ & Erosion Strain & $2.00000 \mathrm{E}+00$ \\
\hline $\begin{array}{l}\text { Intact Strength Constant, } \\
\mathrm{P}_{2}(\mathrm{kPa})\end{array}$ & $1.00000 \mathrm{E}+07$ & Type of Geometric Strain & Instantaneous \\
\hline
\end{tabular}




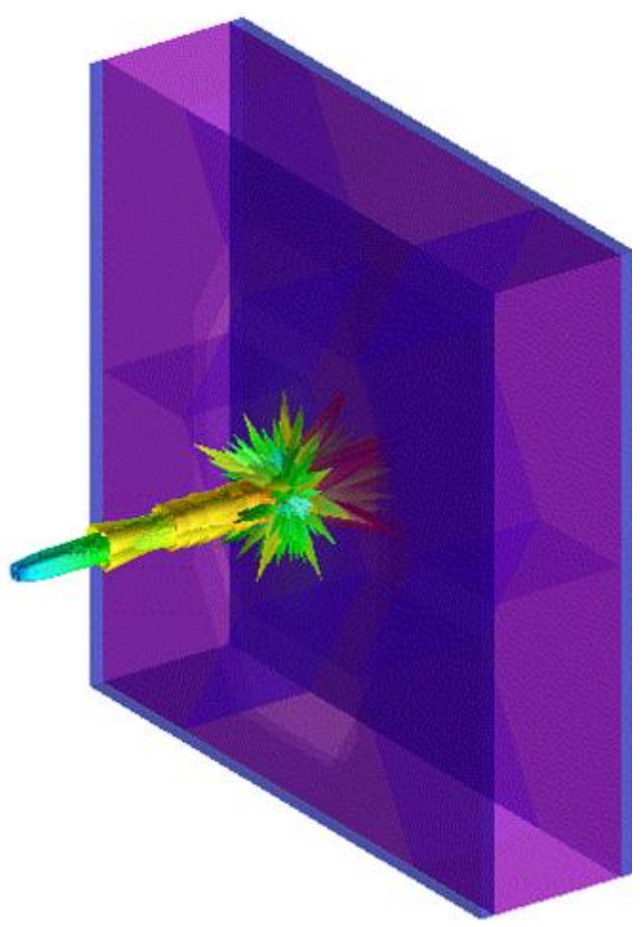

Fig. 1 Threat Include Shaped-Charge Rounds Affecting Honeycomb Armour.
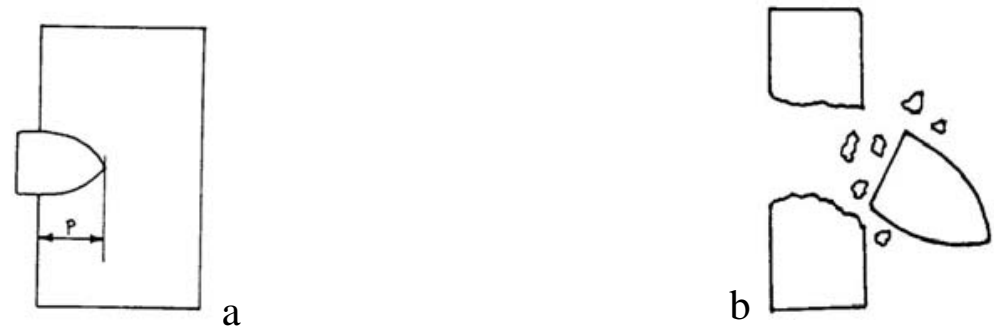

Fig. 2 Penetration and Perforation Phenomena [5].
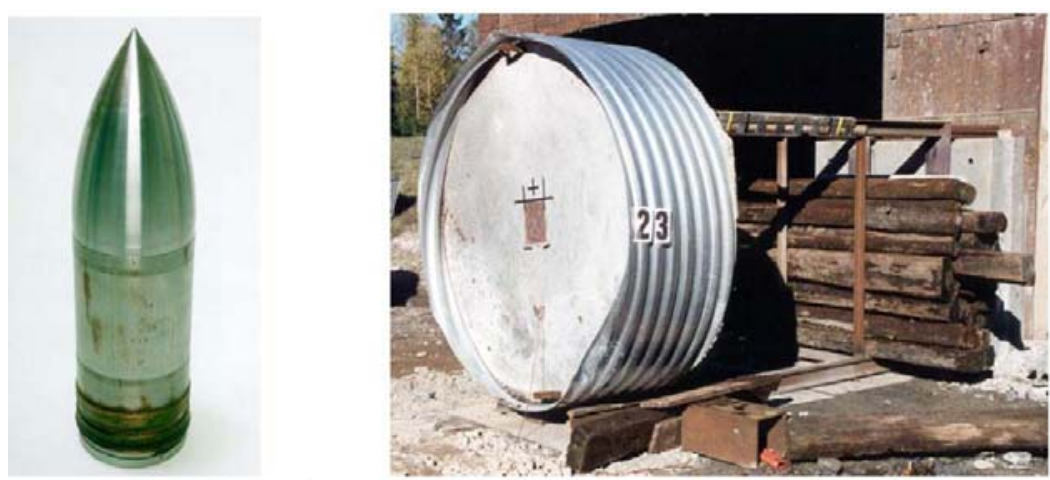

Fig. 3 The Steel Projectile, Concrete Target used for the Benchmark Test [6]. 


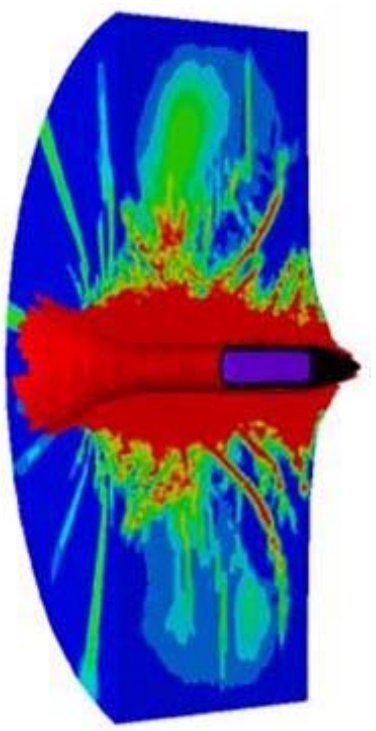

Hansson [6]

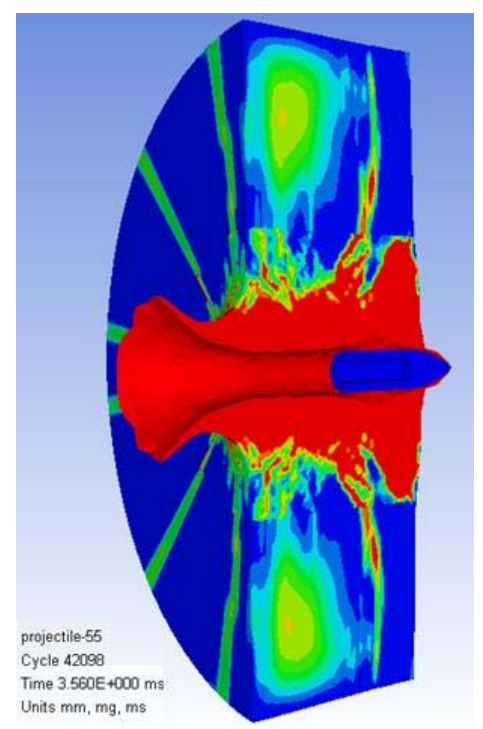

Present Study (1/2-Symmetry)

Fig. 4 Damage Comparison Obtained by Reference [6] and This Study.

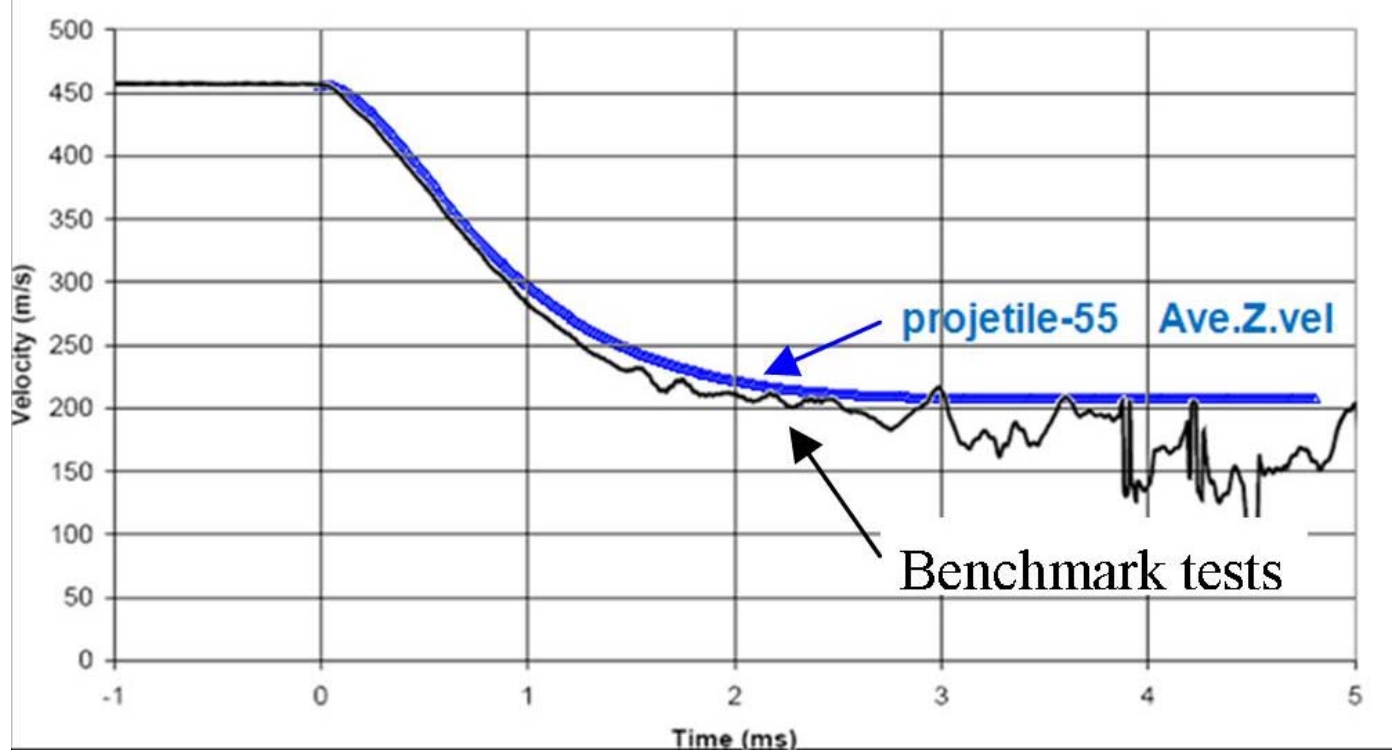

Fig. 5 Mean Velocity Comparison Obtained by Reference [6] and Present Study. 

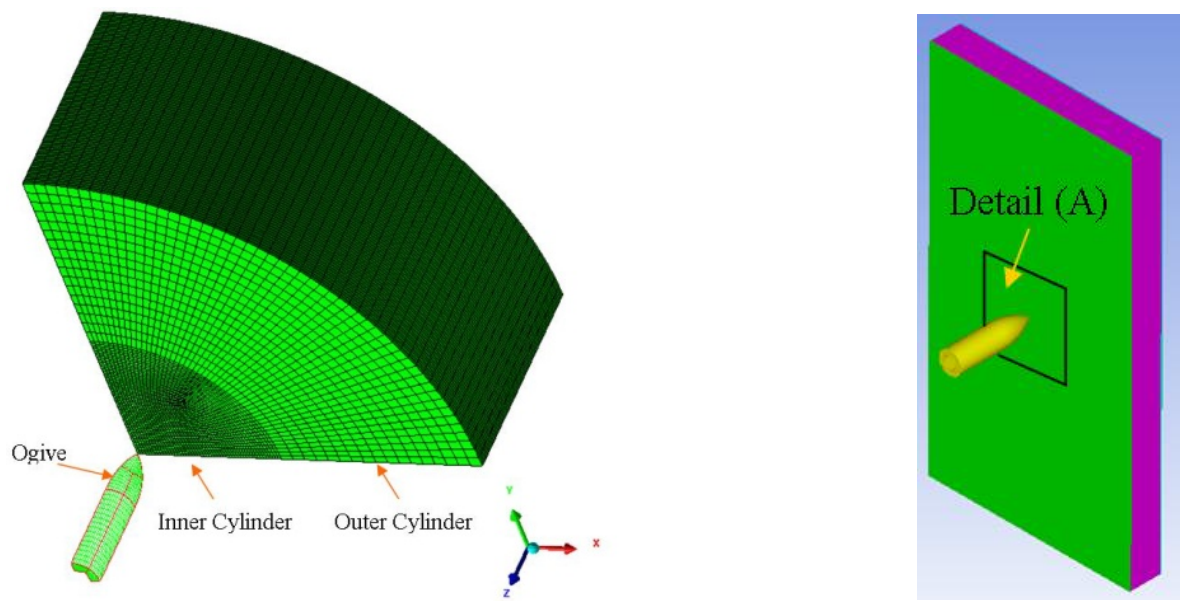

Fig. 6 Meshing of the Tested Model (1/4- Fig. 7 General Model, Location of detail symmetry) for Verification.

(A).
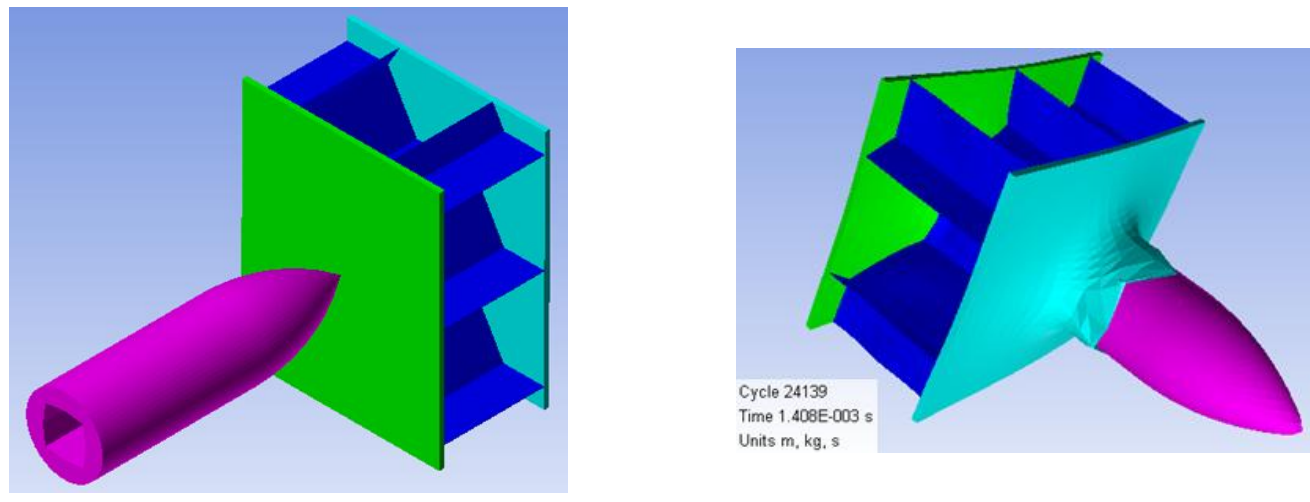

Fig. 8 Detail ( A) Model 1 at $t=0$ and $t=1.408 E-003$ sec.
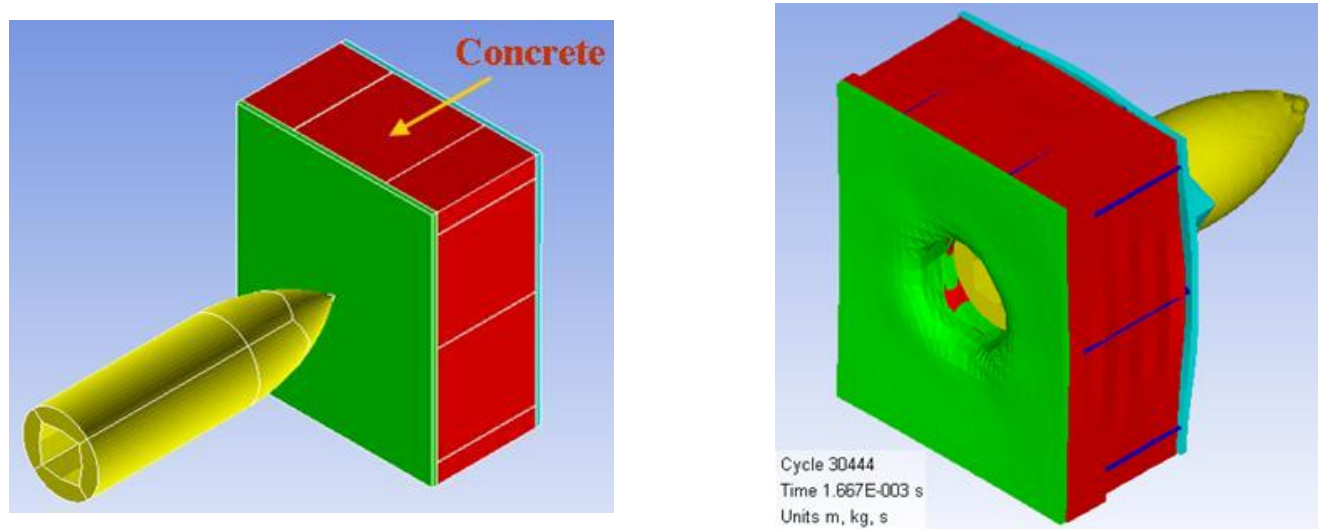

Fig. 9 Detail ( A) Model 2 at $t=0 \mathrm{~s}$ and $\mathrm{t}=1.667 \mathrm{E}-003 \mathrm{sec}$. 

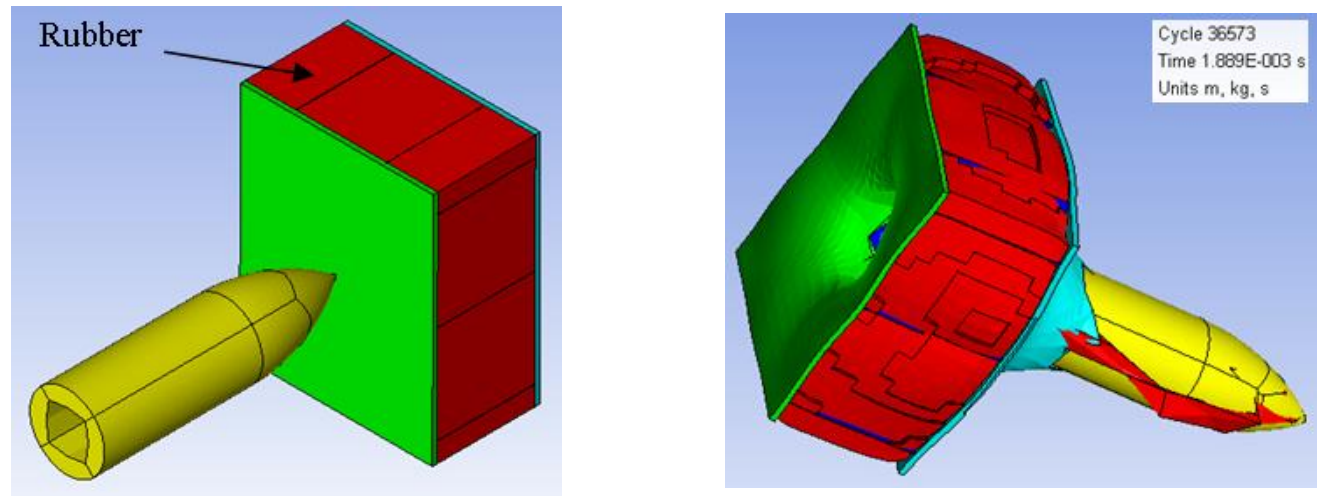

Fig. 10 Detail ( A) Model 3 at $t=0 \mathrm{~s}$ and $t=1.889 E-003$ sec.
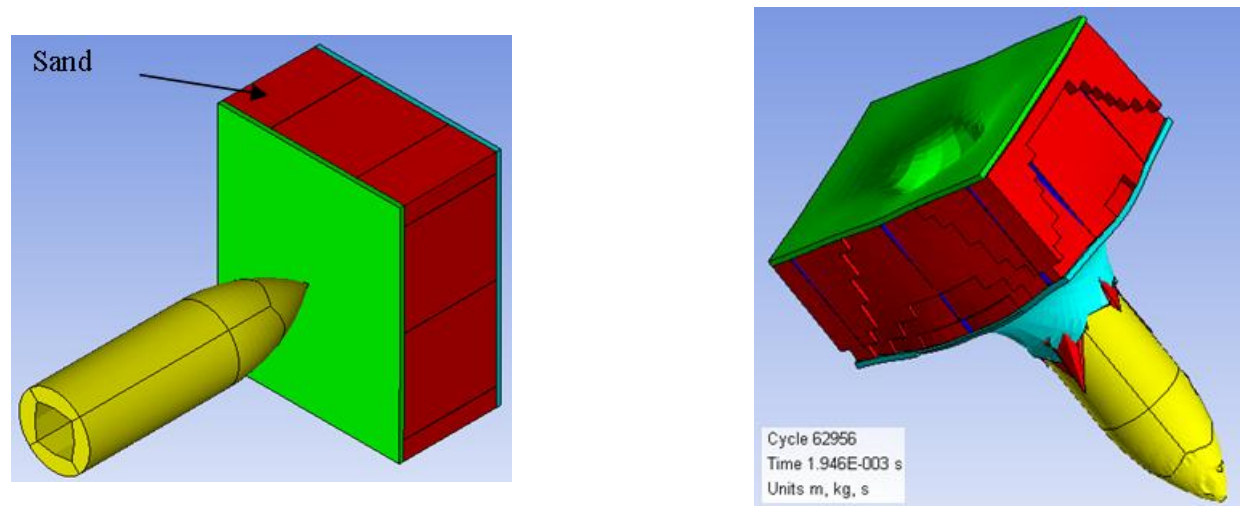

Fig. 11 Detail ( A) Model 4 at $t=0 \mathrm{~s}$ and $t=1.946 E-003$ sec.
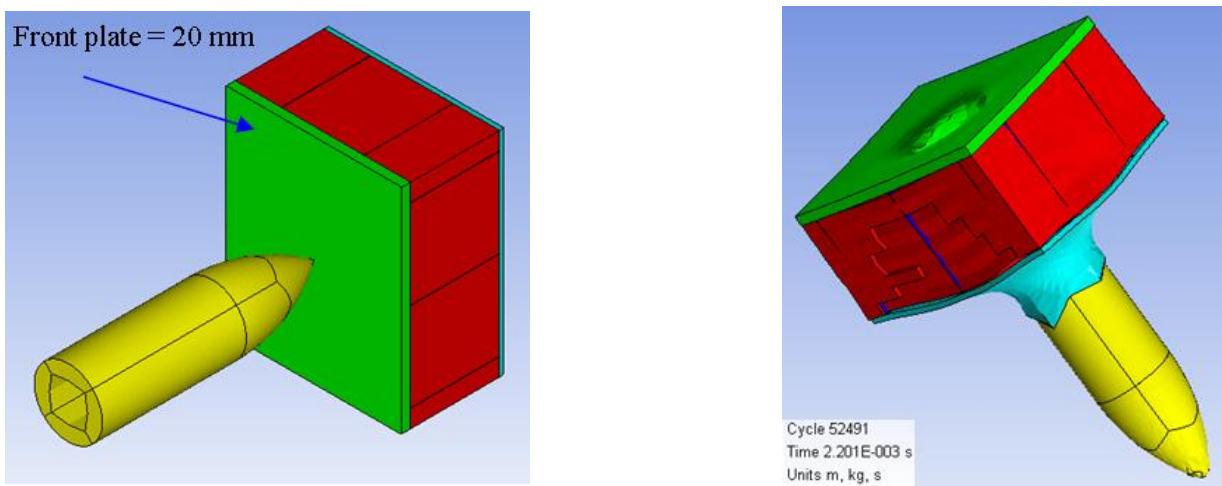

Fig. 12 Detail ( A) Model 5 at $t=0$ sec and $t=2.201 E-003$ sec. 

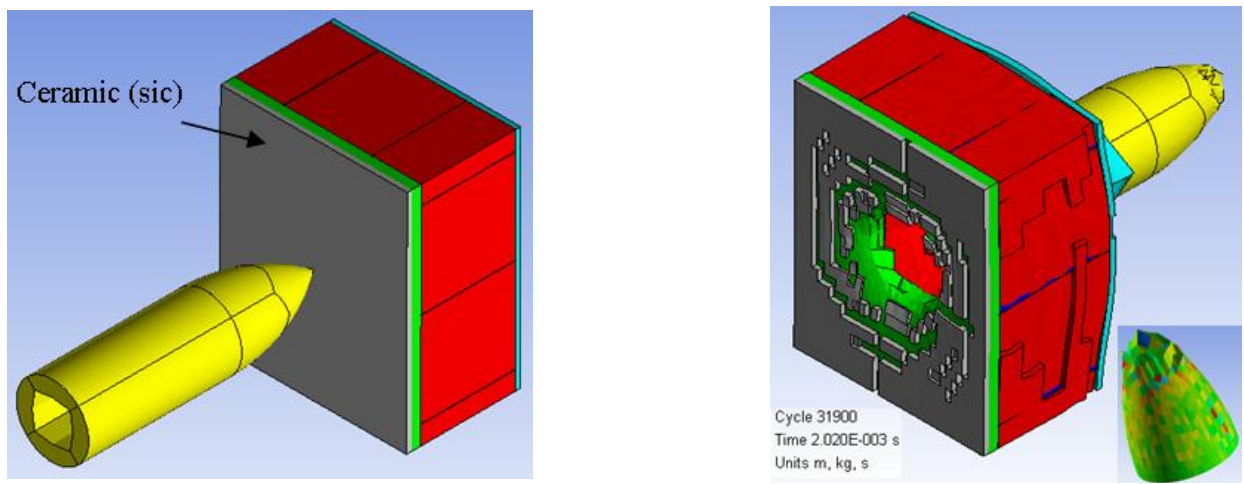

Fig. 13 Detail (A) Model 6 at $t=0$ sec and $t=2.012 E-003$ sec.
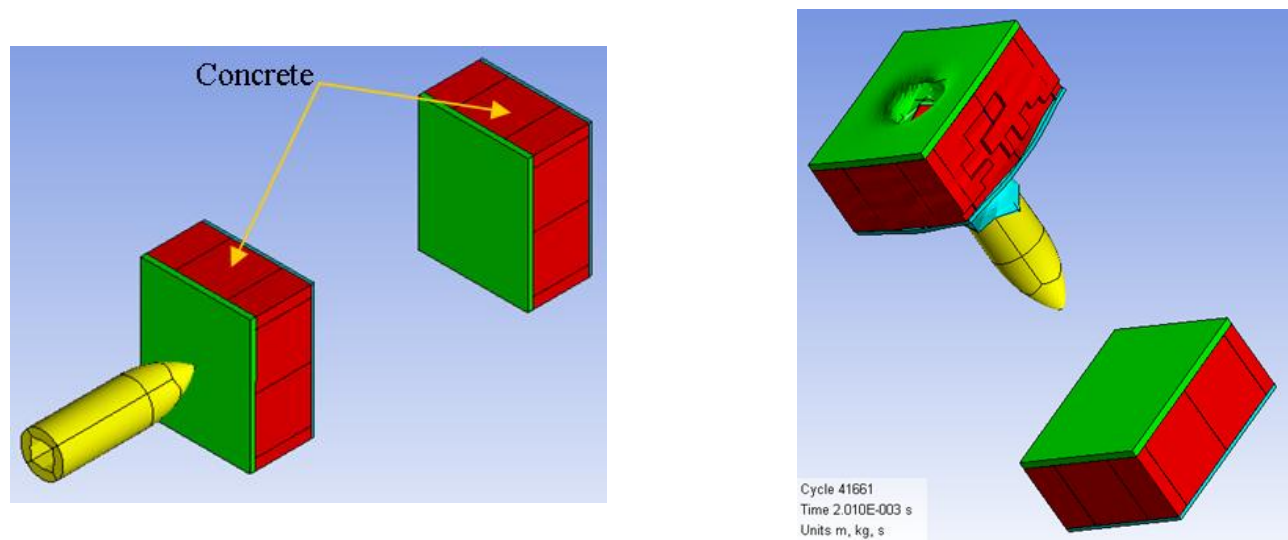

Fig. 14 Detail ( A) Model 7 at $t=0 \mathrm{~s}$ and $t=2.01 E-003$ sec.

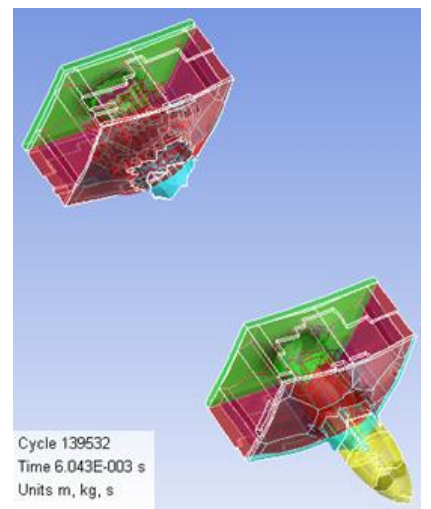

Fig. 15 Detail ( A) Model 7 at $\mathrm{t}=6.043 \mathrm{E}-003$ sec. 

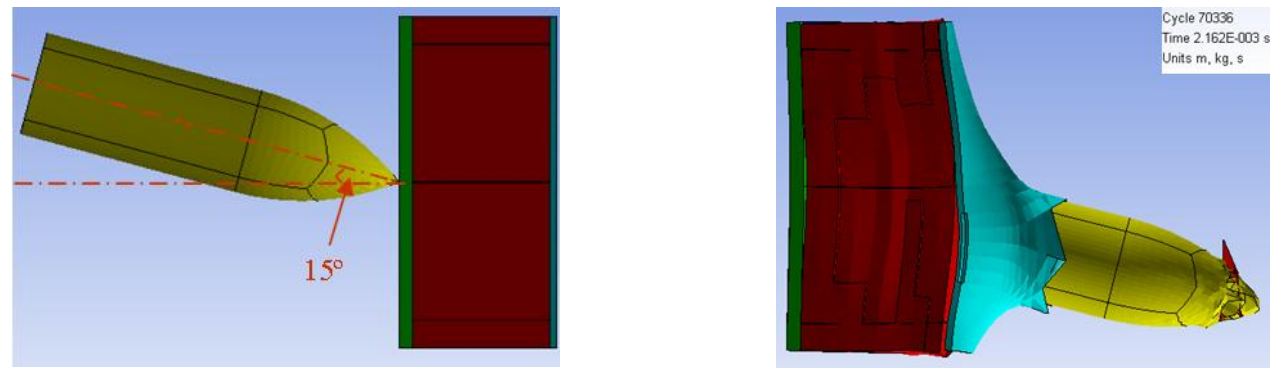

Fig. 16 Detail (A) Model 8 at $t=0$ sec and $t=2.162 E-003$ sec.
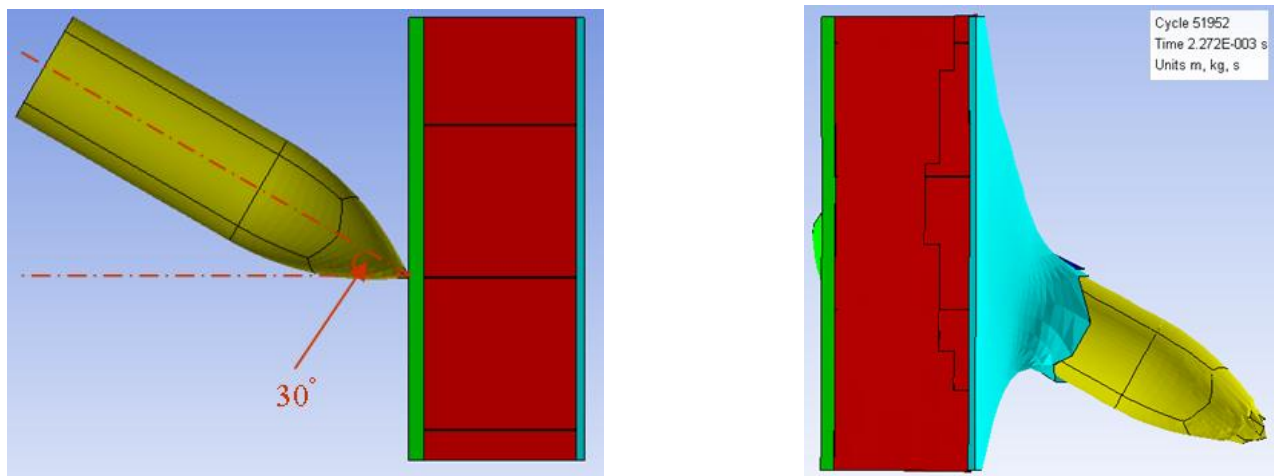

Fig. 17 Detail (A) Model 9 at $t=0$ sec and $t=2.272 E-003$ sec.
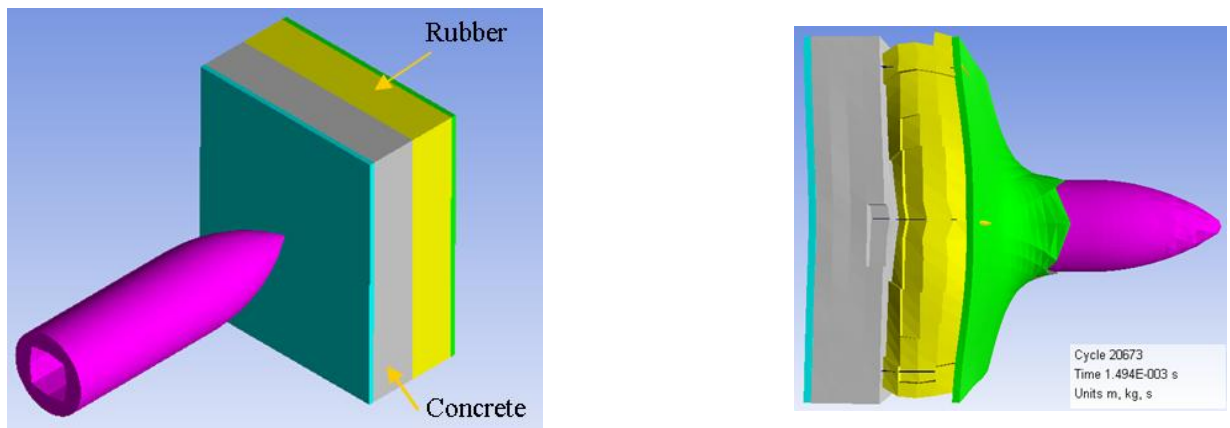

Fig. 18 Detail ( A) Model 10 at $t=0 \mathrm{~s}$ and $t=1.494 E-003$ sec. 


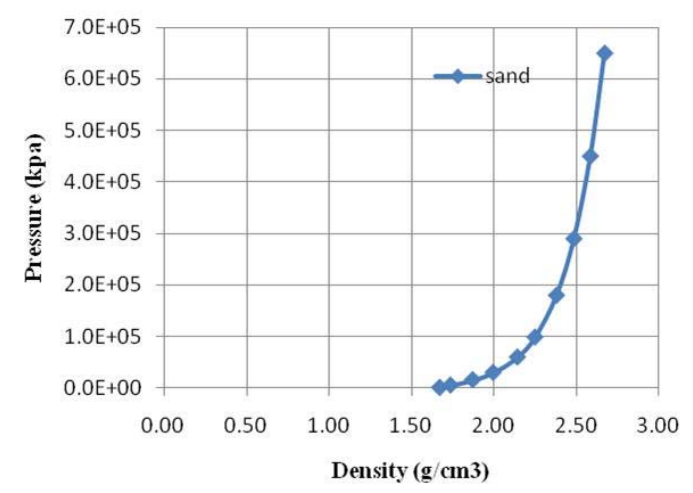

Fig. 19 Density-Pressure Diagram for Sand.

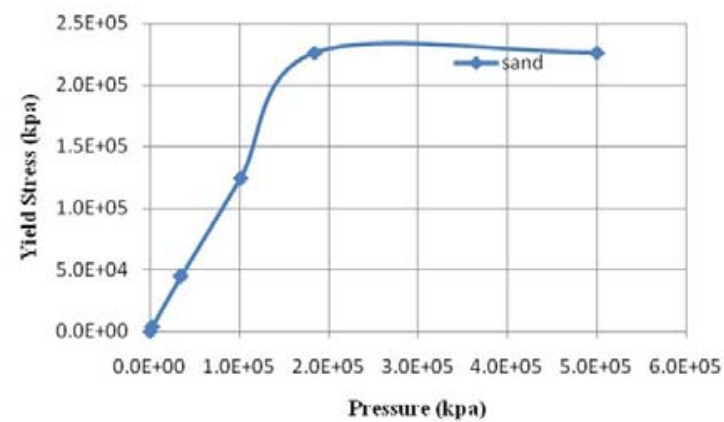

Fig. 21 Pressure-Yield Stress Diagram for Sand.

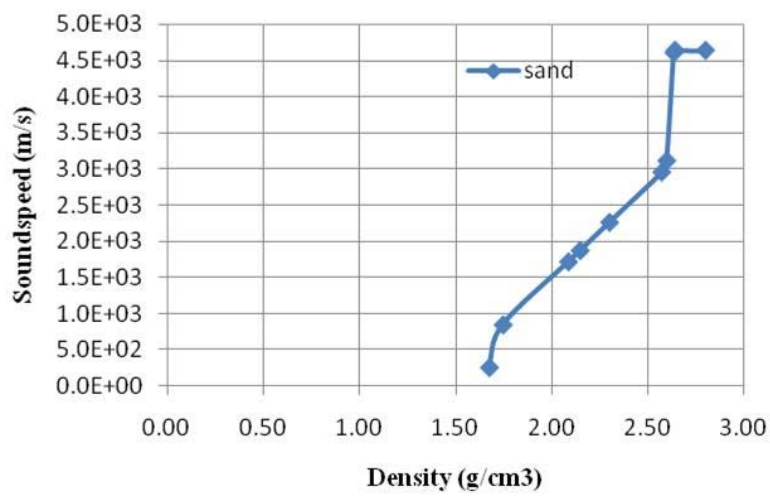

Fig. 20 Density-Soundspeed Diagram for Sand.

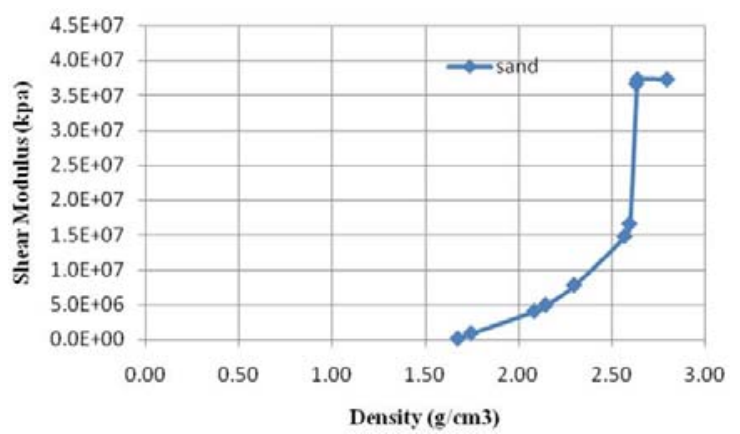

Fig. 22 Density-Shear Modulus Diagram for Sand.

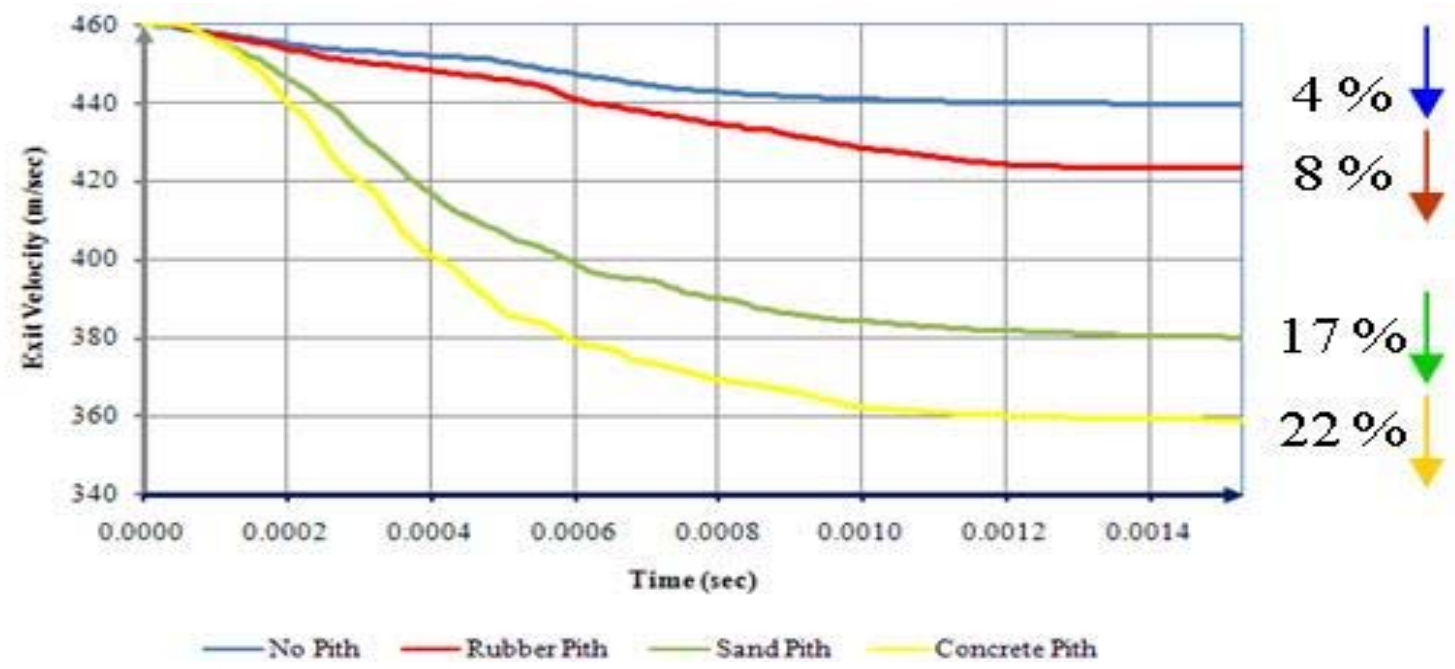

Fig. 23a Projectile Exit-Velocity Vs. Time Due to Multi Material (Group1). 


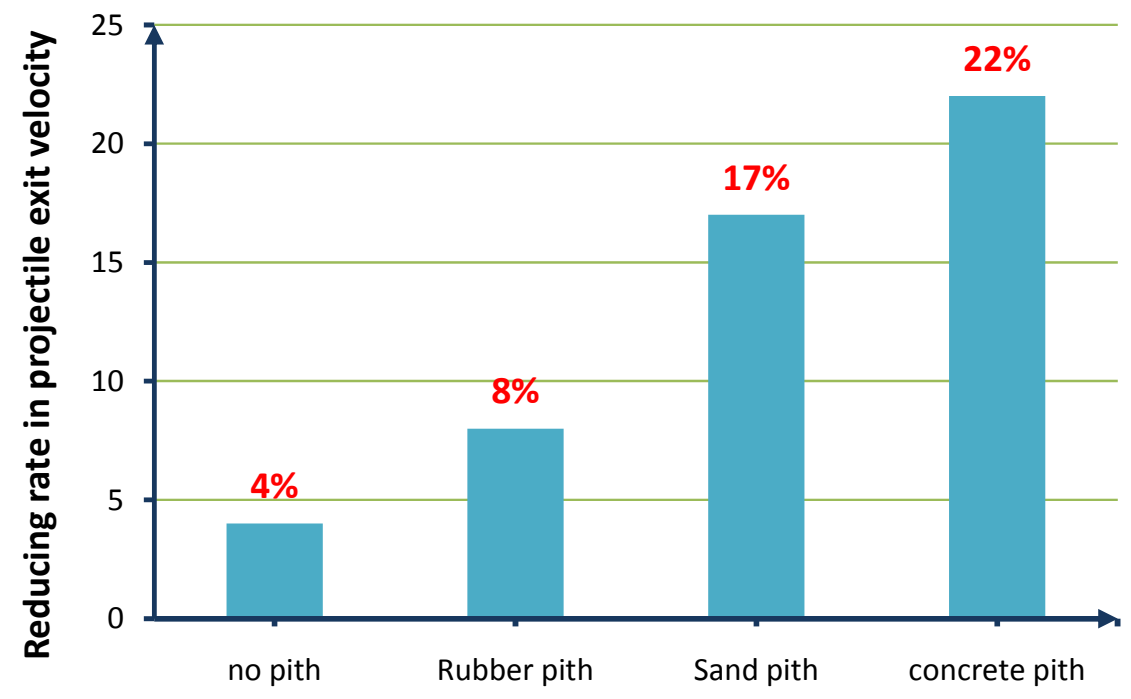

Filler Materials

Fig. 23b Projectile Exit-Velocity Due to Multi Material (Group1).

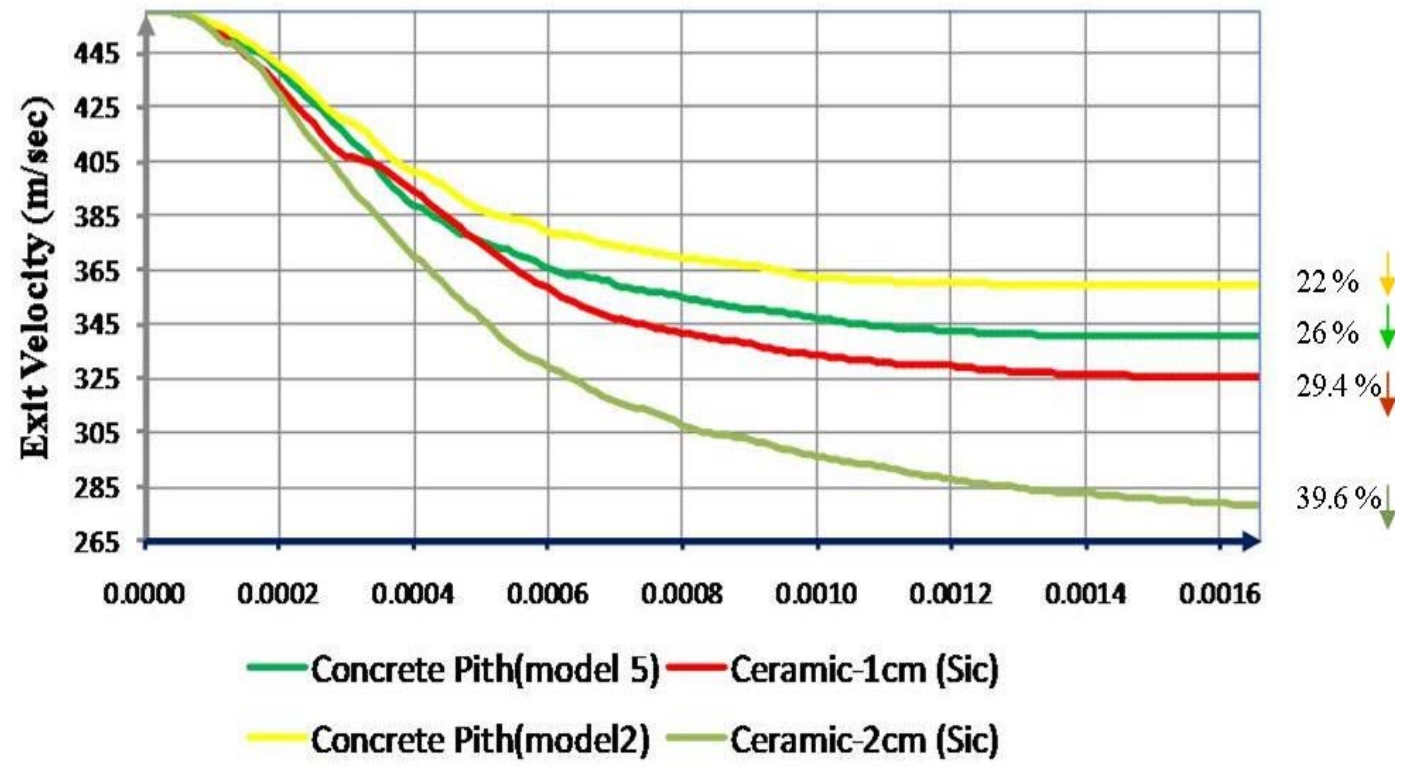

Fig. 24 Projectile Exit-Velocity Vs. Time Due to Concrete, Ceramic (SiC). 


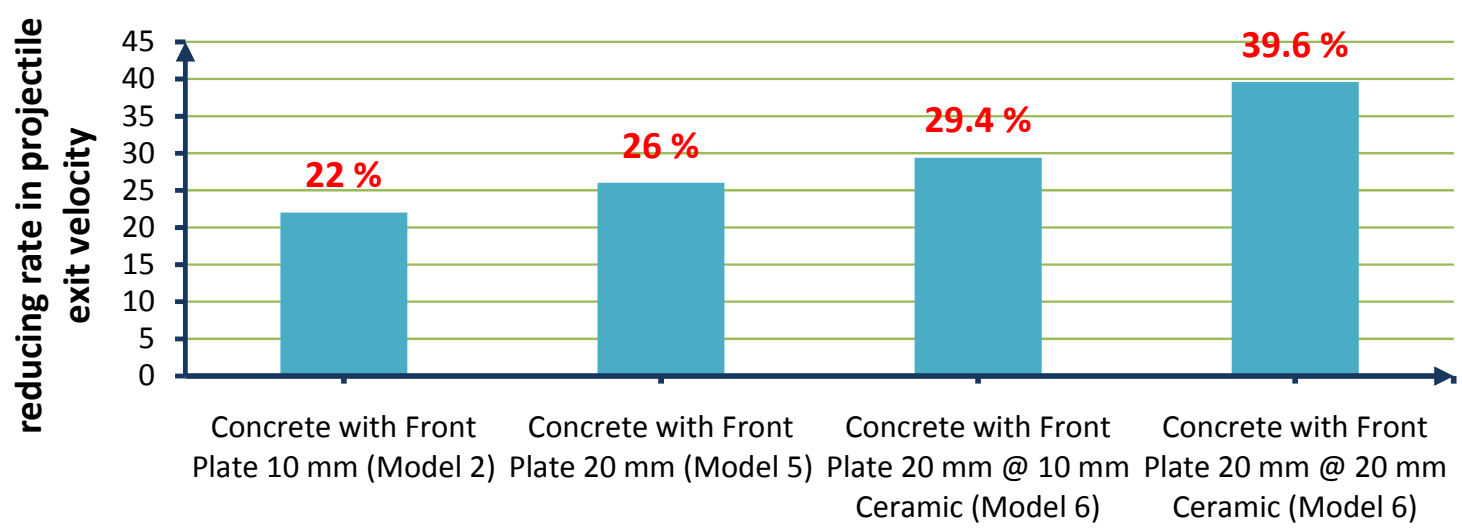

Fig. 25 Projectile Exit-Velocity Due to Concrete, Ceramic (SiC).

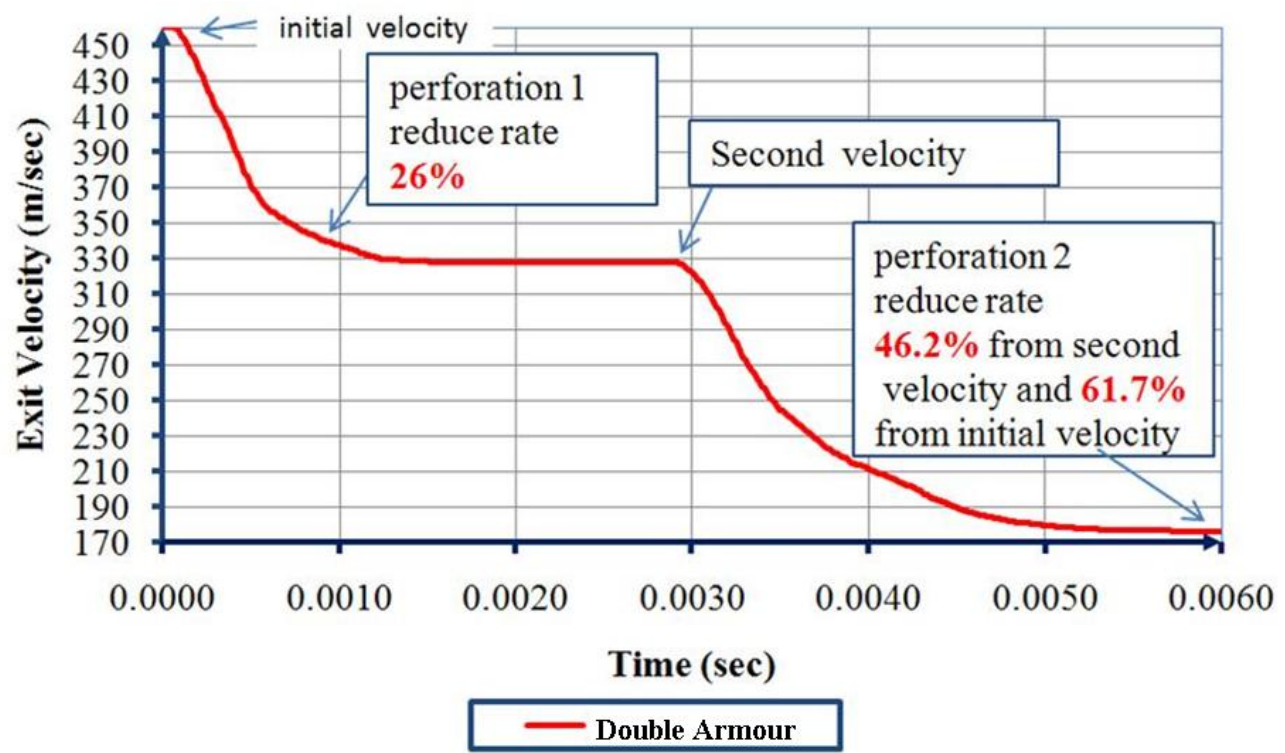

Fig. 26 Projectile Exit-Velocity Vs. Time Due to Double Armours.

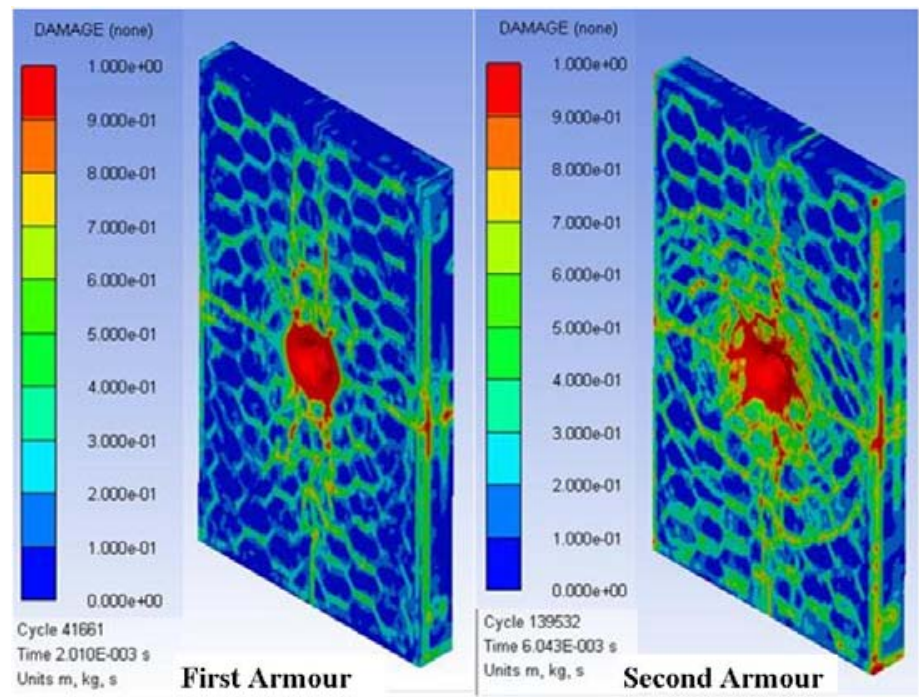

Fig. 27 Distribution of the Damage in Concrete Pith in First and Second Armours. 


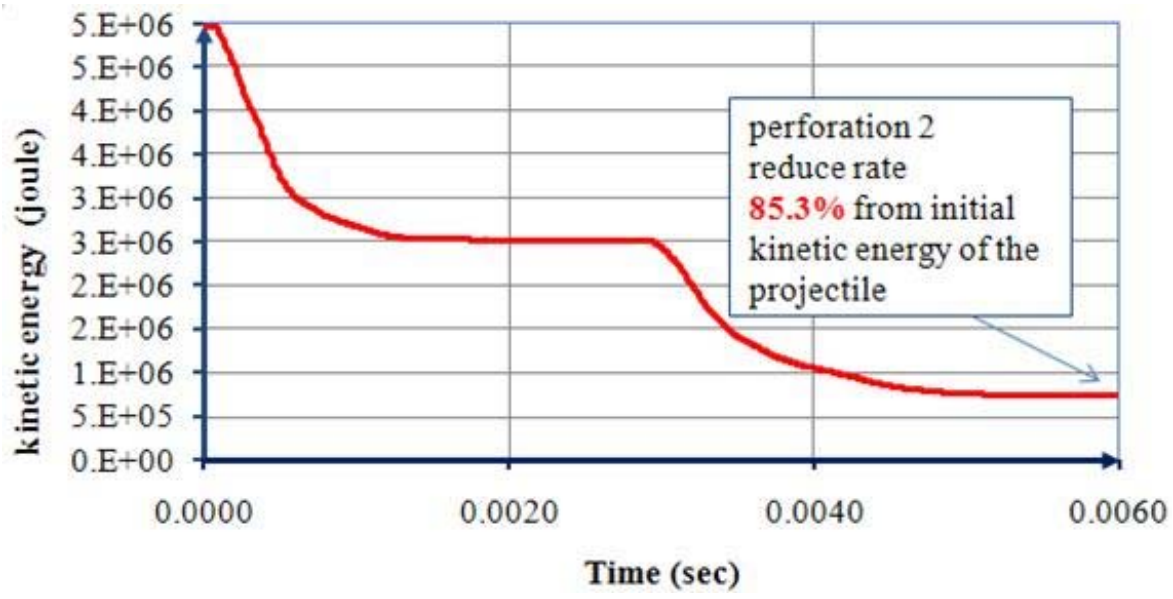

Fig. 28 Kinetic Energy Time History for the Projectile Passing Through Two Armours.

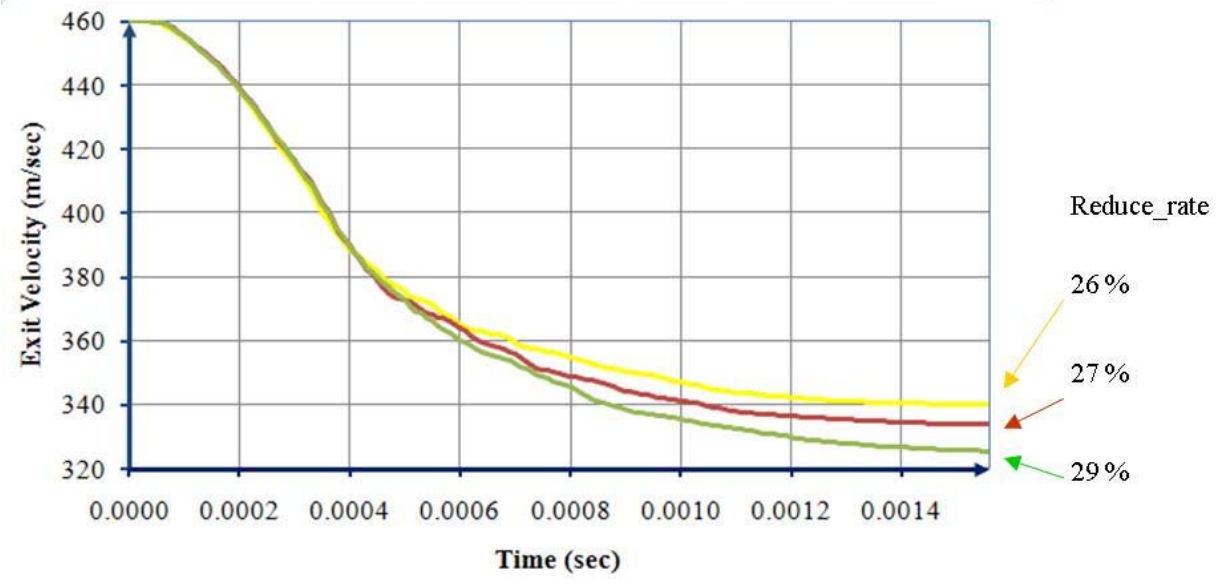

Normal- $90^{\circ}$-oblique- $15^{\circ}-$ oblique $-30^{\circ}$

Fig. 29 Projectile Exit-Velocity Vs. Time Due to Normal and Oblique Impact.

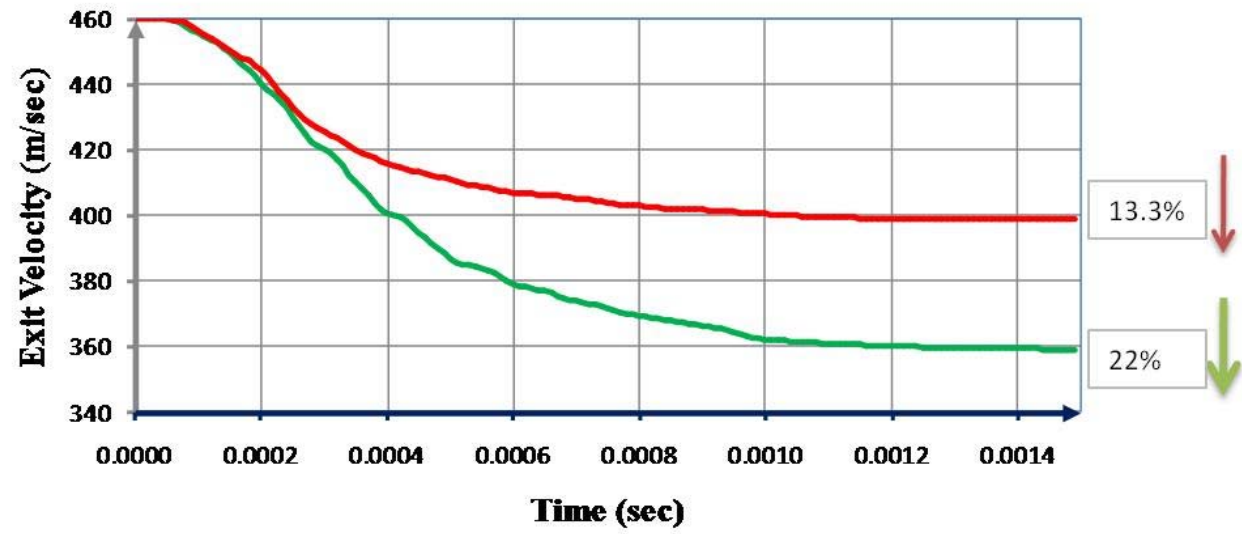

Fig. 30 Projectile Exit-Velocity Vs. Time Due to Model 2 and Model 10. 


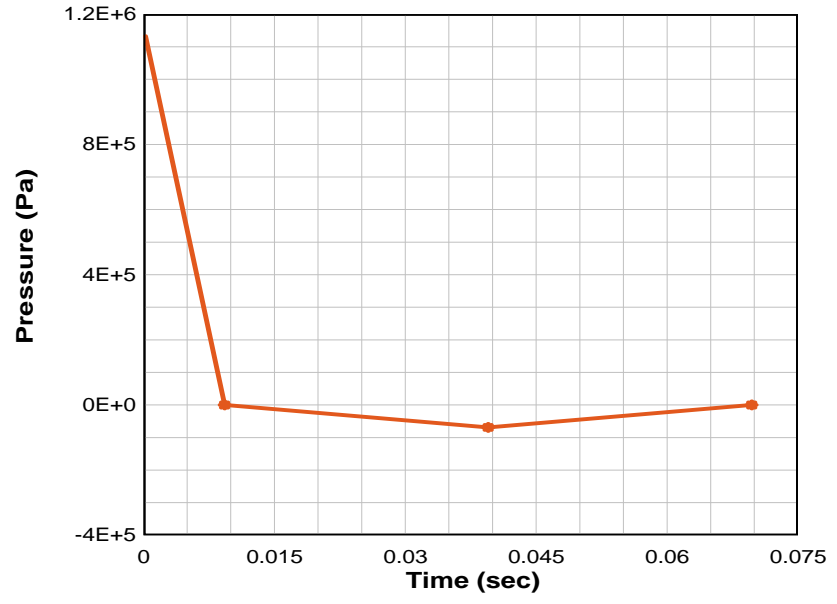

Fig. 31 Blast Loads used to Test the Models of Group 1.

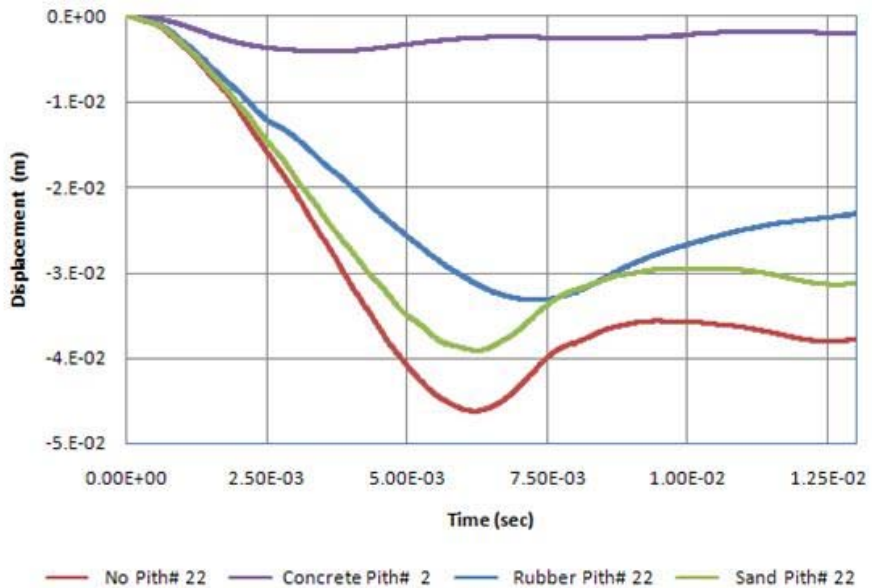

Fig. 32 Displacement Vs. Time for the Models (1, 2, 3 and 4) Subjected to Blast Loads.

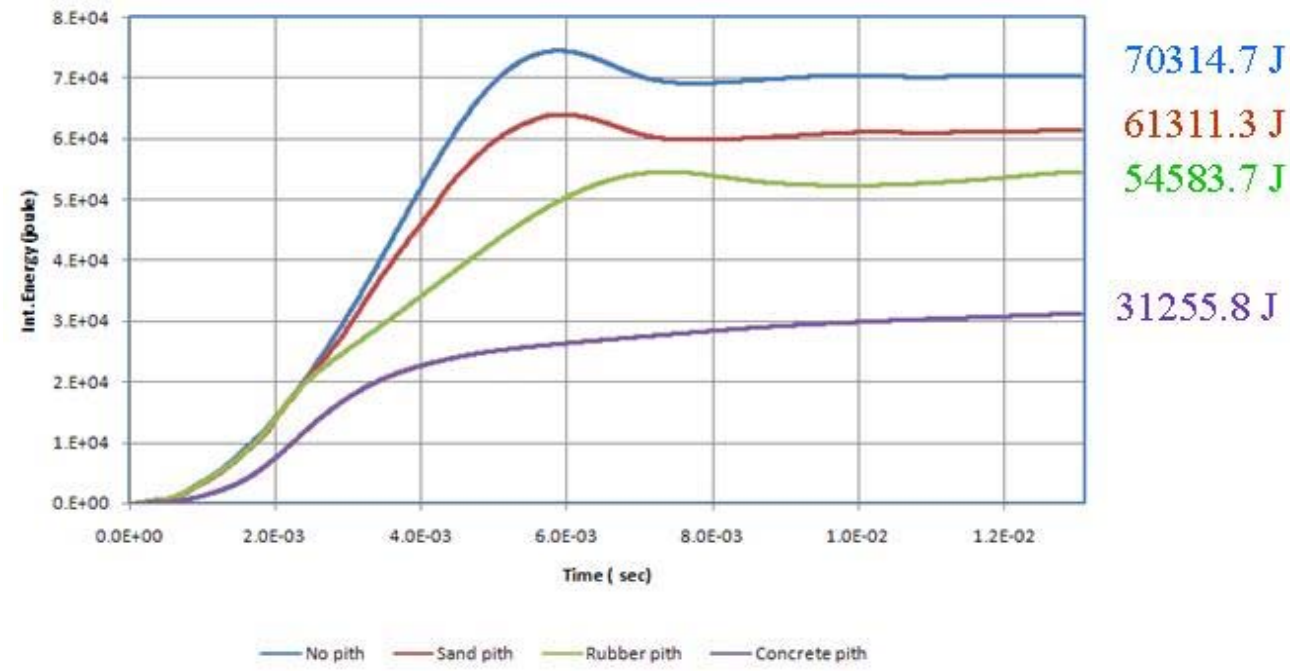

Fig. 33 Internal Energy Vs. Time in all Components of the Models of Group 1. 

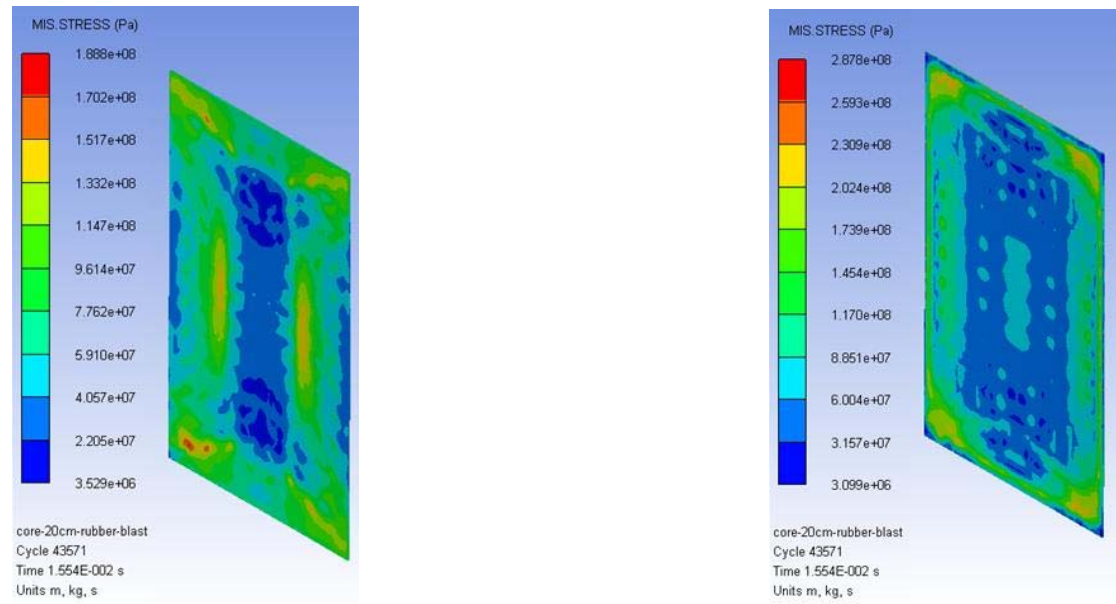

Fig. 34 The Stresses Propagated in the Front (Left) and Back Plate (Right) in Model 3 (Rubber Pith) at Time 1.554E-002 sec.

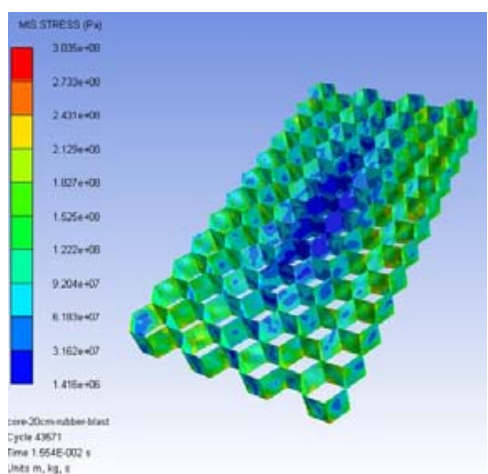

Fig. 35 The Stresses Propagated in The Core in Model 3 (Rubber Pith) at Time 1.554E-002 sec.

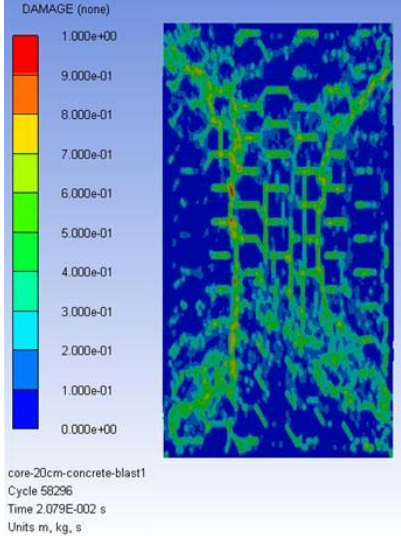

Fig. 36 The Damage Propagated in the Concrete in Model 2 (Concrete Pith) at Time 2.079E-002 sec.

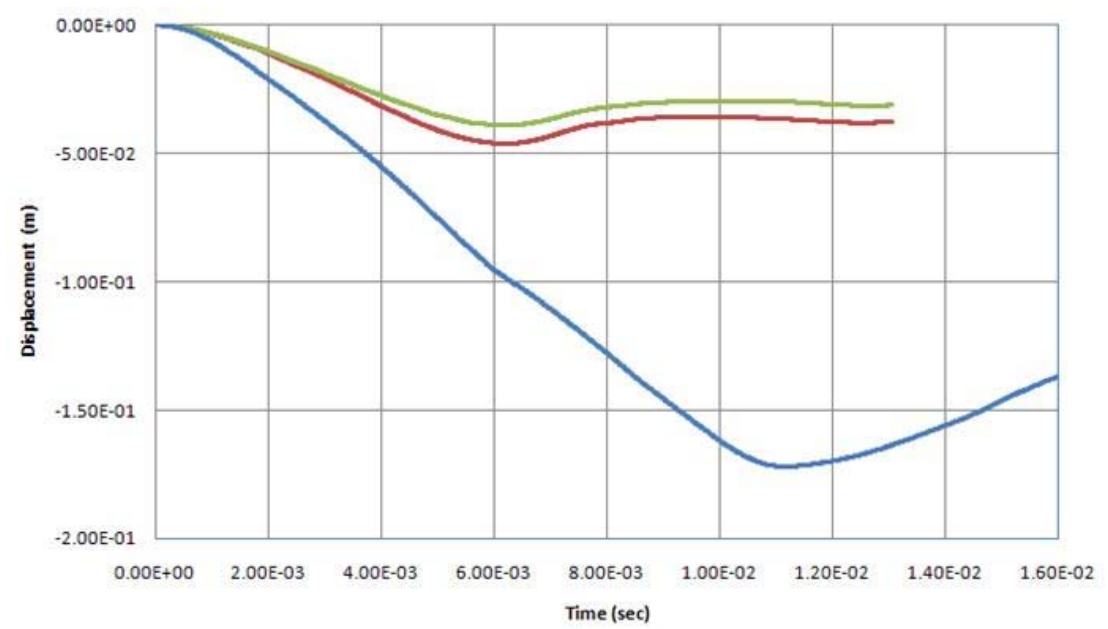

Fig. 37 Displacement Vs. Time for the Model 1 (No Pith), Model 4 (Sand Pith) and Model 11 (Sand Pith without Honeycomb) 